\title{
'Sticky' neutrophils, pathergic arthritis, and response to heparin in pyoderma gangrenosum complicating ulcerative colitis
}

\author{
A D Dwarakanath, L G Yu, C Brookes, D Pryce, J M Rhodes
}

\begin{abstract}
Pyoderma gangrenosum is strongly associated with inflammatory bowel disease and exhibits pathergy, occurring at sites of previous minor trauma. A patient is presented with a 21 year history of extensive ulcerative colitis, who developed pyoderma gangrenosum and arthralgia while receiving high dose corticosteroids for active ulcerative colitis. The arthralgia exhibited pathergy affecting particularly the left temporomandibular joint, which was stressed by an asymmetric bite, and the left elbow, which had been fractured many years previously. This prompted the hypothesis that neutrophils in this condition may be marginated, as a result of increased stickiness of either the neutrophil or the vascular endothelium. The introduction of heparin therapy was associated with rapid resolution of the arthralgia, pyoderma gangrenosum, and ulcerative colitis.

(Gut 1995; 37: 585-588)
\end{abstract}

Keywords: pyoderma gangrenosum, ulcerative colitis, pathergic arthritis, heparin, neutrophils.

Pyoderma gangrenosum is strongly associated with inflammatory bowel disease, particularly ulcerative colitis, which coexists in 34 to $81 \% .^{12}$ It may occur at any site, commonly affecting the legs, and exhibits pathergy - that is, occurring at sites of previous minor trauma such as needle puncture. ${ }^{3}$ Its presence is not closely related to the activity of colitis and it may even occur after colectomy. ${ }^{4}$

In up to $55 \%$ of cases pyoderma gangrenosum is associated with an arthritis ${ }^{6}$ that may behave more aggressively than the acute seronegative arthropathy that commonly complicates active inflammatory bowel disease. ${ }^{7}$ The arthritis may affect smaller joints and can be erosive, ${ }^{89}$ sometimes resembling rheumatoid arthritis. ${ }^{10}$

Conventional therapy is empirical, usually

Department of Medicine, University of Liverpool, Liverpool A D Dwarakanath

L G Yu

C Brookes

D Pryce

J M Rhodes

Correspondence to: Professor J M Rhodes Professor J M Rhodes, Department of Medicine, Liverpool L69 3BX.

Accepted for publication 24 February 1995 prednisolone $60 \mathrm{mg} /$ day), but various other agents have been tried with occasional success including topical antibiotics, corticosteroids, azathioprine, cyclosporine, disodium cromoglycate, and dapsone. ${ }^{11-15}$ In cases associated with colitis it may benefit, albeit unpredictably, from bowel resection.

The pathogenesis of pyoderma gangrenosum is unclear. It shares several features with Behcet's disease including associated inflammatory bowel disease, arthritis, and pathergy. ${ }^{16-18}$
In both conditions neutrophil abnormalities have been reported, including decreased migration into skin windows, reduced chemotaxis, abnormal phagocytosis, and decreased bactericidal activity. ${ }^{14}{ }^{19-21}$

In the case presented here the pathergic nature of the patient's arthritis led us to the hypothesis that increased neutrophil adherence to vascular endothelium might be the underlying abnormality. The marginated neutrophils would then be ready to migrate into adjacent tissue in response to minor local trauma. In view of the report of a reduction in the sulphated proteoglycan content of the vascular endothelium in inflammatory bowel disease ${ }^{22}$ we speculated that heparin therapy might reverse this defect and reduce neutrophilendothelium adherence.

\section{Case report}

A 42 year old woman with a 21 year history of extensive ulcerative colitis, developed a typical violaceous ulcerating lesion of pyoderma gangrenosum over the left ankle (Fig 1) at a time when her colitis was moderately active. She is a lifelong non-smoker and has no family history of inflammatory bowel disease. Her colitis had not been in complete remission for 20 months and for the two months prior to the development of the skin lesion she had required oral corticosteroid therapy (prednisolone $\geqslant 30 \mathrm{mg} /$ day) with which she was compliant, in addition to her usual maintenance therapy of sulphasalazine $1 \mathrm{~g}$ twice daily. Two weeks before the appearance of the skin lesion she had developed a widespread severe arthralgia particularly affecting the left temporomandibular joint, left elbow, both knees, and ankle joints. She has an asymmetric bite and the affected temporomandibular joint was on dental review noted to be susceptible to trauma as a result of this asymmetry; similarly the painful elbow had been fractured many years previously but had been pain free for years. The pain from the left temporomandibular joint was so severe she could not take solid food.

On admission haemoglobin was $10 \cdot 1 \mathrm{~g} / \mathrm{dl}$,

erythrocyte sedimentation rate $46 \mathrm{~mm}$ in one albumin $38 \mathrm{~g} / \mathrm{l}$. Sigmoidoscopy shortly before admission showed liquid stool and red granular mucosa. A biopsy was not taken from the skin lesion because of the risk of poor healing at that site. In view of the pronounced rise in faecal lactoferrin excretion that we have noted in inflammatory bowel disease $\mathrm{e}^{23}$ and the 


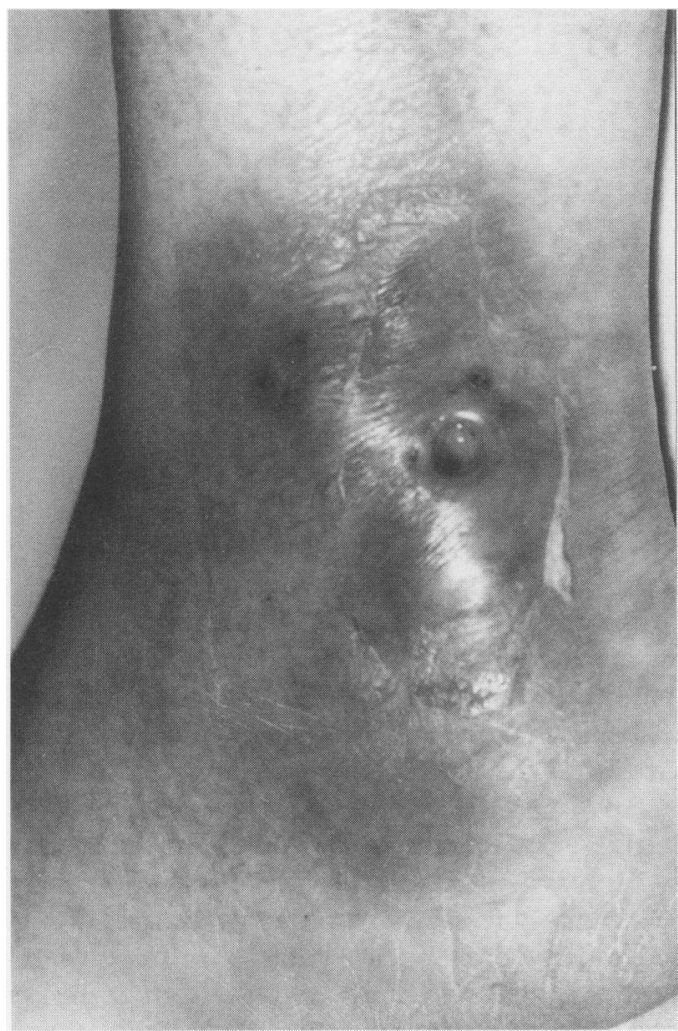

Figure 1: Lesion of pyoderma gangrenosum above the left ankle before the introduction of heparin therapy.

role of lactoferrin in promoting neutrophil adhesion, ${ }^{24-27}$ serum lactoferrin was measured using a sandwich enzyme linked immunosorbent assay (ELISA) and found to be $489 \mathrm{ng} / \mathrm{ml}$, compared with $144 \mathrm{ng} / \mathrm{ml}$ (95\% confidence limits 17 to 270) for control serum samples $(n=18$, healthy controls age 16 to 55$)$. Neutrophil adhesion to plastic tissue culture plates was measured by incubation of $10^{6}$ neutrophils in 1 ml RPMI1640 (Gibco, Paisley, UK) for 30 minutes at $37^{\circ} \mathrm{C}$ on 24 well culture plates (Nunc, Kamstrup, Denmark) followed by washing three times with phosphate buffered
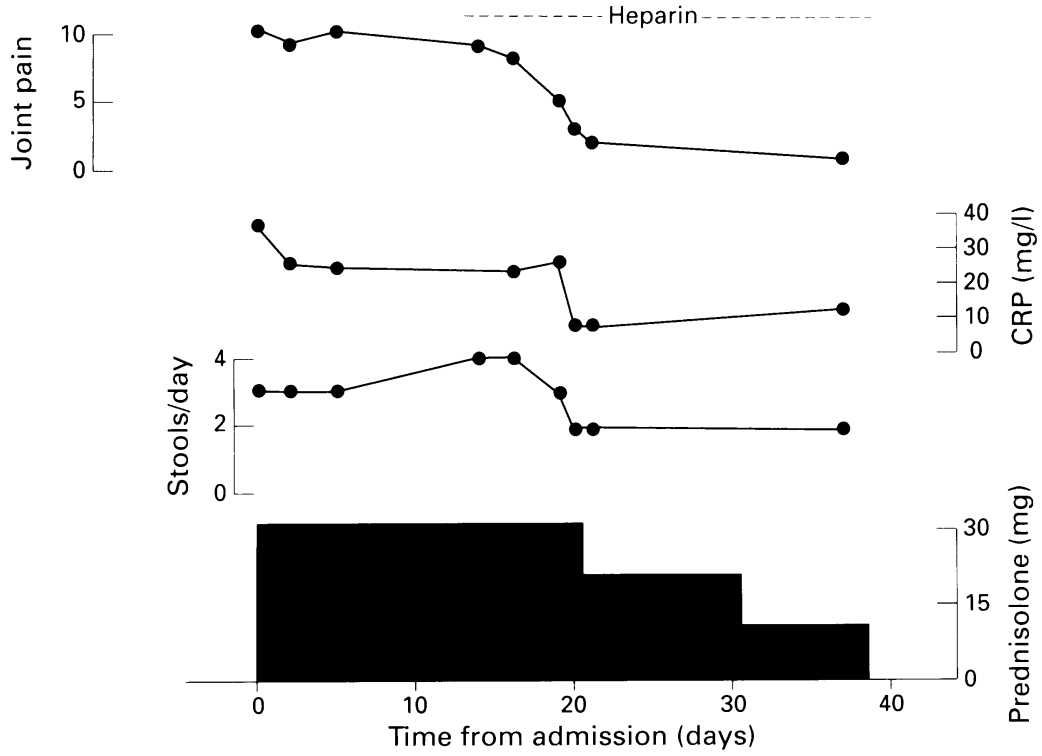

Figure 2: The patient's clinical course, before and after the introduction of heparin therapy, illustrating the improvement in joint pain, stool frequency, and falling serum $C$ reactive protein, these changes occurring while the dose of prednisolone was decreased. Foint pain was assessed using a visual analogue scale. $C R P=C$ reactive protein. saline $\mathrm{pH} 7 \cdot 4$, staining with Wright's stain (Sigma Chemical, Poole, UK), and counting of adherent neutrophils in eight high power fields after blind labelling. Neutrophil adhesion was consistently increased (median 59 per high power field (range 30-84, 18 findings)), compared with median 27 (range 2-45) for neutrophils from healthy controls $(n=4)$.

Intravenous heparin (30000 units/24 hours) was started, with the activated partial thromboplastin ratio between 1.5 and 2.0 , and the corticosteroid therapy maintained unchanged at prednisolone $30 \mathrm{mg}$ once daily. There was a rapid improvement in the arthropathy such that she was able to chew a normal diet within two days and there was a decrease in bowel frequency from four liquid stools to two formed stools daily in association with sigmoidoscopic improvement at that time (Fig 2). After 10 days of intravenous heparin therapy, maintenance therapy with subcutaneous calcium heparin was introduced, maintaining an activated partial thromboplastin ratio between 1.5 and $2 \cdot 0$. It was possible to withdraw the prednisolone completely and there was gradual resolution of the pyoderma gangrenosum (Fig 3 ). The serum $C$ reactive protein and serum albumin both improved during heparin therapy (Fig 2). Sixteen months later the patient remains well without corticosteroid therapy with colitis in complete remission, skin lesion healed, and no joint pain.

\section{Discussion}

The dramatic response to heparin in this patient is in keeping with the hypothesis that increased neutrophil-endothelial adherence resulted in generalised margination of neutrophils, which in turn was responsible for the pyoderma gangrenosum and pathergic arthritis. Neutrophil adherence to endothelium was recognised by Dutrochet in 1824 to be an essential initial step of the acute inflammatory response. $^{28}$ In pyoderma gangrenosum we speculate that this increased adhesion becomes a more generalised abnormality, either of the neutrophils themselves or of vascular endothelium, and results in neutrophil margination at sites distant from the inflamed bowel. This margination would readily explain the pathergy that typifies the skin lesions (and in this case also the joint involvement).

It is probable that one of the properties of the endothelial sulphated proteoglycans is local inhibition of thrombin formation ${ }^{29}$ and that the reduction in endothelial sulphated proteoglycan shown in inflammatory bowel disease $^{22}$ would impair this effect and in turn lead to increased leucocyte adhesion. The increased mucosal ${ }^{23}$ and serum lactoferrin ${ }^{30}$ content would add to this effect - as lactoferrin is highly charged and a potent stimulator of neutrophil adherence. ${ }^{24-27}$ Increased neutrophil adherence to nylon, a charge dependent phenomenon, has been reported in inflammatory bowel disease. ${ }^{31}$

Heparin, which is itself a sulphated proteoglycan, has a wide range of effects that can be considered anti-inflammatory; these include: 


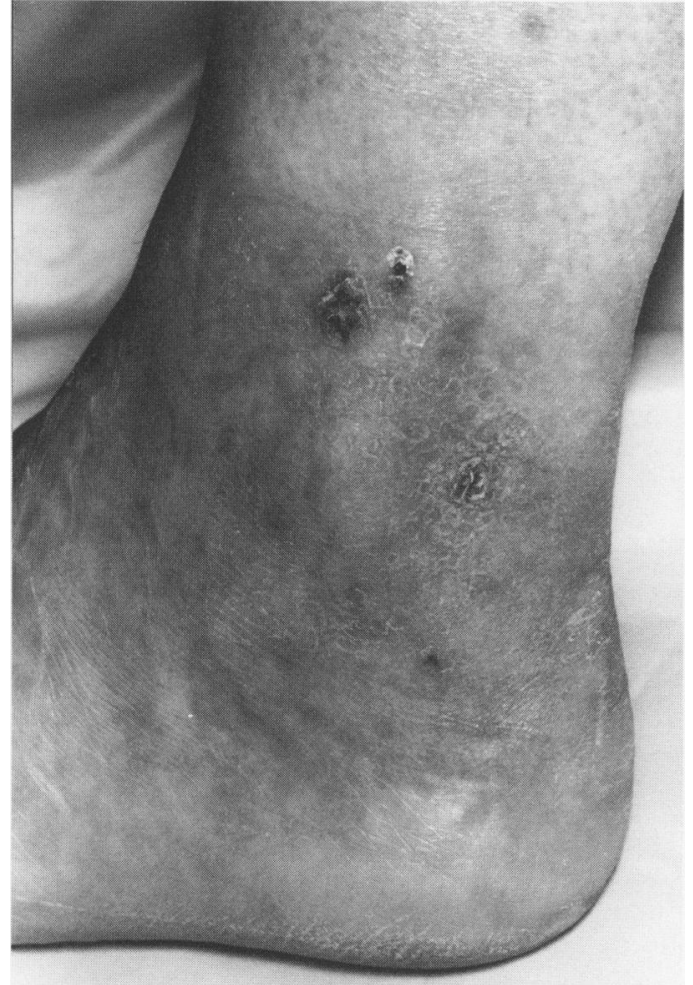

Figure 3: Complete healing of the pyoderma gangrenosum eight weeks after the introduction of heparin therapy.

(a) inhibition of local formation of thrombin, which itself activates neutrophils ${ }^{32} 33$ and increases the permeability of endothelial cell layers, ${ }^{34}$ (b) inhibition of neutrophil elastase, ${ }^{35}$ which is essential for penetration of the endothelium by the neutrophil, (c) binding of chemokines, involved in margination and adhesion, ${ }^{3637}$ (d) inhibition of leucocyte heparanase, ${ }^{38-40}$ (e) binding of lactoferrin. ${ }^{41}$ Many or all of these properties are also held by the normal endothelial proteoglycans (particularly heparan sulphate). If the endothelial effects are critical as seems likely, the long half life of endothelial bound ${ }^{42}$ heparin may mean that intermittent treatment with minimal systemic anticoagulation could be used to achieve this effect on neutrophil-endothelial adhesion.

Increased neutrophil adherence to endothelium resulting in neutrophil margination provides a plausible explanation for pathergy in pyoderma gangrenosum. The impressive effects of heparin therapy in this case, and in cases of refractory ulcerative colitis ${ }^{43-45}$ suggests a need for further therapeutic trials in both conditions.

ADD was a National Association for Colitis and Crohn's Disease/British Digestive Foundation research fellow. LGY is supported by a grant from the North West Cancer Research Fund.

1 Callen JP, Taylor WB. Pyoderma gangrenosum - a literature review. Cutis 1978; 21 : 61-4.

2 Powell FC, Schroeter AL, Su WPD, Perry HO. Pyoderma gangrenosum: review of 86 patients. $Q \mathcal{F}$ Med 1985; 55: gangrenosur.

3 Hickman JG, Lazarus GS. Pyoderma gangrenosum: a reappraisal of associated systemic diseases. $\mathrm{Br} \mathcal{F}$ Dermatol 1980; 102: 235-7.

4 Cook TJ, Lorincz AL. Pyoderma gangrenosum appearing 10 years after colectomy and apparent cure of chronic ulcerative colitis. Arch Dermatol 1962; 55: 105-6.

5 Holmlund DEW, Wahlby L. Pyoderma gangrenosum after colectomy for inflammatory bowel disease. Acta Chir Scand 1987; 53: 73-4
6 Levitt MD, Ritchie JK, Lennard-Jones JE, Phillips RK. Pyoderma gangrenosum in inflammatory bowel disease. Br F Surg 1991; 78: 676-8.

7 Van der Sluis. Two cases of pyoderma gangrenosum associated with the presence of an abnormal serum protein. ated with the presence of an ab
Dermatologica 1966; 132: 409-24.

8 Ayres S Jr, Ayres S III. Pyoderma gangrenosum with an unusual syndrome of ulcers, vesicles and arthritis. Arch

9 Griffiths HJ, Sundaram M. Pyoderma gangrenosum and erosive peripheral arthritis. Can Assoc Radiol f 1986; 37: 125-7.

10 Lazarus GS, Goldsmith LA, Rocklin RE, Pinals RS, De Buisseret J-P, David JR, et al. Pyoderma gangrenosum altered hypersensitivity and polyarthritis. Arch Dermatol 1972; 105: 46-51.

11 Michaelsson G, Malin L, Ohman S, Gip L, Lindstrom B, Skogh M, et al. Colfazimine: a new agent for the treatment of pyoderma gangrenosum. Arch Dermatol 1976; 112: 344-9.

12 Soto $\mathrm{LD}$. Diaminodiphenylosulfone and steroids in the treatment of pyoderma gangrenosum. Int 7 Dermatol treatment of pyoc

13 Saffouri B, Hom BM, Mertesdorf JM, Gardiner JE. Treatment of pyoderma gangrenosum with disodium cromoglycate. Dig Dis Sci 1984; 29: 183-5.

14 Holt PJ, Davies MG, Saunders KC, Nak G. Pyoderma gangrenosum: clinical and laboratory findings in 15 patients with special reference to polyarthritis. Medicine (Baltimore) 1980; 59: 114-33.

15 Walling A, Sweet D. Pyoderma gangrenosum. Am Fam Physician 1987; 35: 159-64.

16 Armas JB, Davies J, Davis $M$, Lovell C, NcHugh N. Atypical Behcet's disease with peripheral erosive arthropathy and pyoderma gangrenosum. Clin Exp Rheumatol pathy and pyoderma

17 Stingl G, Hintner H, Wolff K. Pyoderma gangrenosum. Hautarzt 1981; 32: 165-72.

18 Framer JL. Behcet's syndrome. Arch Dermatol 1970; 102: 116-7.

19 Shore RN. Pyoderma gangrenosum, defective neutrophil chemotaxis, and leukaemia. Arch Dermatol 1976; 112: 1792-3.

20 Jacobs JC, Goetzl EJ. 'Streaky leucocyte factor', arthritis, and pyoderma gangrenosum. F Pediatr 1975; 56: 570-8.

21 Breathnach SM, Wells GC, Valdimarsson H. Idiopathic pyoderma gangrenosum and impaired lymphocyte function: failure of azathioprine and corticosteroid therapy. $\mathrm{Br}$ f Dermatol 1981; 104: 567-73.

22 Murch SH, MacDonald TT, Walker-Smith JA, Levin M, Lionetti P, Klein NJ. Disruption of sulphated glycosaminoglycans in intestinal inflammation. Lancet 1993; 341: 711-4

23 Dwarakanath AD, O'Dowd GM, Beasley C, Tsai HH, Hart CA, Rhodes JM. Lactoferrin is present in normal mucosal mast cells, is selectively excreted in faeces in inflammatory bowel disease and may be relevant to leucocyte recruitment. Gut 1993; 34 (suppl 4): S28.

24 Oseas R, Yang HH, Baehner RL, Boxer LA. Lactoferrin: a promoter of polymorphonuclear leucocyte adhesiveness. Blood 1981; 57: 939-45.

25 Boxer LA, Coates TD, Haak RA, Wolach JB, Hoffstein S, Cehrs $\mathrm{K}$, et al. Human neutrophil-specific granule deficiency: a model to assess the role of neutrophil-specific ciency: a model to assess the role of neutrophil-specific granules in the evolution
Blood 1982; 59: 1317-23.

26 Boxer LA, Haak RA, Yang HH, Wolach JB, Whitcomb J, Butterick C, et al. Membrane-bound lactoferrin alters the surface properties of polymorphonuclear leucocytes. $\mathcal{f}$ Clin Invest 1982; 70: 1049-55.

27 Boxer LA, Bjorksten B, Bjork J, Yang HH, Allen JM, Baehner RL. Neutropenia induced by systemic infusion of lactoferrin. $\mathcal{F}$ Lab Clin Med 1982; 99: 866-72.

28 Dutrochet M. Recherches anatomiques et physiologiques sur la structure intime des animaux et des vegetaux, et sur Leur Motilite. Paris: Bailliere et fils, 1824.

29 Zimmerman GA, McIntyre TM, Prescott SM. Thrombin stimulates the adherence of neutrophils to human endothelial cells in vitro. 7 Clin Invest 1985; 76: 2235-46.

30 Adeyemi EO, Hodgson HJF. Lactoferrin: a correlate of disease activity in inflammatory bowel disease. European fournal of Gastroenterology and Hepatology 1991; 3: 51-6.

31 Cason J, Ainley CC, Wolstencoft RA, Thompson RPH. Polymorphonuclear leucocytes in Crohn's disease and ulcerative proctocolitis: association between enhanced adherence to nylon fibre and disease variables. $\mathcal{F}$ Clin Pathol 1988; 41: 241-6.

32 Bar-Sharit R, Benezra M, Sabbah V, Bode W, Vlodovsky I. Thrombin as a multifunctional protein: induction of cell adhesion and proliferation. Am $\mathcal{F}$ Respir Cell $\mathrm{Mol}$ Biol 1992; 6: 123-30.

33 Vercellotti GM, Moldow CF, Wickham NW, Jacob HS. Endothelial cell platelet-activating factor primes neutrophil responses: amplification of endothelial activation trophil responses: amplification of endothelial activation

34 Huang AJ, Manning JE, Bandak TM, Ratau MC, Hanser Kuang AJ, Manning JE, Bandak TM, Ratau MC, Hanser
KR Silverstein SC. Endothelial cell cytosolic free calcium regulates neutrophil migration across monolayers of regulates neutrophil migration across monol

35 Walsh RL, Dillon TJ, Sciccitano R, Mclennan G. Heparin and heparan sulphate are inhibitors of human leucocyte elastase. Clin Sci 1991; 81: 341-6.

36 Miller MD, Krangel MS. Biology and biochemistry of the chemokines: a family of chemotactic and inflammatory cytokines. Crit Rev Immunol 1992; 12: 17-46. 
37 Tanaka Y, Adams DH, Hubscher S, Hirano H, Siebenlist $\mathrm{U}$, Shaw S. T-cell adhesion induced by proteoglycanimmobilised cytokine MIP-1 B. Nature 1993; 361: immob.

38 Key NS, Platt JH, Vercellotti GM. Vascular endothelial cell proteoglycans are susceptible to cleavage by neutroThromb 1992; 12: 836-42.

39 Lider O, Baharm E, Mekari YA, Miller T, Naparstek Y, Vlodavsky I, Cohen IR. Suppression of experimental autoimmune diseases and prolongation of allograft survival by treatment of animals with low doses of heparins. F Clin Invest 1989; 83: 752-6.

40 Vlodavsky I, Eldor A, Haimovitz-Friedman A, Matzner Y, Ishai-Michaeli $R$, Lider $O$, et al Expression of heparanase by platelets and circulating cells of the immune system: by platelets and circulating cells of the immune system:
possible involvement in diapedesis and extravasation.
Invasion Metastasis 1992; 12: 112-27.

41 Zou S, Magura CE, Hurley WL. Heparin-binding properties of lactoferrin and lysozyme. Comp Biochem Physiol 1992; 103B: 889-95.

42 Hiebert LM, Wice SM, McDuffie MN, Jacques LB. The heparin target organ - the endothelium. Studies in a rat model. $Q$ F Med 1993; 86: 341-8.

43 Gaffney PR, O'Leary JJ, Doyle CT, Gaffney A, Hogan J, Smew F, et al. Response to heparin in patients with ulcerative colitis. Lancet 1991; 337: 238-9.

44 Gaffney PR, Doyle CT, Hogan J, Gaffney A. Paradoxical response to heparin in 10 patients with ulcerative colitis. Gastroenterology 1993; 104: A703.

45 Zavgorodniy LG, Mustyats AP. The use of anticoagulants in combined therapy of non-specific colitis. Klin Med 1982; 60: 74-80. 